\title{
Hemodynamic effects of carbetocin administered as an intravenous bolus or infusion during cesarean delivery
}

\section{Kihyug Kwon, Dohyung Kim, Hyunmin Jo, Ji Eun Park, and Kyung Ok Kim}

Department of Anesthesiology and Pain Medicine, Dongguk University llsan Hospital, Goyang, Korea
Received August 7, 2019

Revised January 28, 2020

Accepted January 31, 2020

\section{Corresponding author}

Kihyug Kwon, M.D.

Department of Anesthesiology and Pain Medicine, Dongguk University Ilsan Hospital, 27 Dongguk-ro, Ilsandong-gu, Goyang 10326, Korea Tel: 82-31-961-7868

Fax: 82-31-961-7869

E-mail: sylph0704@naver.com

\begin{abstract}
Background: Postpartum hemorrhage is the leading cause of maternal mortality. Oxytocin being the most popular uterotonic agent, has been routinely administered after both vaginal delivery and cesarean section. Carbetocin is a newer uterotonic agent and provides the benefit of a longer duration of action without additional administration post-delivery.
\end{abstract}

Methods: We recruited 34 women undergoing elective cesarean section under spinal anesthesia. All patient was received spinal anesthesia using 0.5\% hyperbaric Marcaine 8-10 mg in conjugation with fentanyl $20 \mu \mathrm{g}$ in the left lateral decubitus position. Hartmann's solution 10-15 ml/kg was administered before carbetocin. The operation started as soon as sensory block at level T4-T6 was confirmed. A non-invasive hemodynamic monitoring cuff (Finometer $\left.{ }^{\circledR}\right)$ was attached to the patient's finger soon after the induction of spinal anesthesia. Using the Finometer, we recorded the heart rate and mean arterial pressure at every $15 \mathrm{~s}$, starting from $15 \mathrm{~s}$ before the administration of carbetocin to $5 \mathrm{~min}$ after. After the removal of the placenta, the bolus group was administered intravenous bolus injection of carbetocin $100 \mu \mathrm{g}$ and the infusion group was administered carbetocin $100 \mu \mathrm{g}$ diluted in $50 \mathrm{ml}$ normal saline, over 5 min using an infusion pump.

Results: The demographic data showed no significant difference between the two groups. Furthermore, there were no significant hemodynamic differences between the two groups.

Conclusions: The method of administration of carbetocin does not influence its hemodynamic effects.

Keywords: Carbetocin; Cesarean section; Hypotension; Tachycardia.

\section{INTRODUCTION}

Postpartum hemorrhage (PPH) is associated with nearly one quarter of all maternal deaths globally. It is also the leading cause of maternal mortality in most low-income countries $[1,2]$. Uterine atony is the most common cause of $\mathrm{PPH}$ [3]. The World Health Organization (WHO) recommends active management of the third stage of labor and use of uterotonics for the prevention of PPH during vaginal delivery and cesarean section [2].

Oxytocin being the most popular uterotonic agent, has been routinely administered after both vaginal delivery and cesarean section [4]. However, it is associated with dose-related side effects, including hypotension, tachycardia, nausea and vomiting [5]. Other reported side effects include pulmonary edema due to the antidiuretic effect of oxytocin $[6,7]$. Thomas et al. [8] compared hemodynamic change between a group that was administered oxytocin by bolus in-

This is an Open Access article distributed under the terms of the Creative Commons Attribution Non-Commercial License (http://creativecommons.org/licenses/by-nc/4.0) which permits unrestricted non-commercial use, distribution, and reproduction in any medium, provided the original work is properly cited.

Copyright (C) the Korean Society of Anesthesiologists, 2020 
jection and another group that was administered oxytocin by infusion. They concluded that the infusion group had lesser hemodynamic changes than the bolus group.

Carbetocin is a newer uterotonic agent and a long-acting synthetic octapeptide analogue of oxytocin with oxytocin receptor agonist properties. Because carbetocin has a 4-10 fold longer elimination half-life than that of oxytocin, it provides the benefit of longer duration of oxytocic action without additional administration in post-delivery [4]. Although the difference between carbetocin and oxytocin in terms of hemodynamic changes, postpartum blood loss and incidence of side effects is not statistically significant $[4,9]$, carbetocin is superior to oxytocin in terms of additional dosing and cost-effectiveness [10].

There is no definite consensus about how to administer carbetocin. We compared the hemodynamic effects of carbetocin when administered as an intravenous bolus and as an infusion over 5 minutes using a non-invasive hemodynamic monitoring device.

\section{MATERIALS AND METHODS}

This study was approved by the Hospital Ethics Committee (Dongguk University Ilsan Hospital Institutional Review Board, registration no. 2012-77). The study was registered with Clinical Research Information Service, Korea (https:// cris.nih.go.kr, registration no. KCT0000715). We recruited 34 women undergoing elective cesarean section under spinal anesthesia. The patients were 37 weeks or more into their pregnancy and were classified as Class 1 or 2 according to the American Society of Anesthesiologists physical status classification system. The patients who had preeclampsia, placenta previa, other diseases affecting hemodynamic change and past medical history of hypertension or diabetes were excluded. The written consent was given by all subjects before operation. The subjects were randomly divided into two groups. Prior to enrolling patients, group assignments were placed in 34 opaque envelopes. These envelopes were mixed and placed in a container. Before each patient entered the operating room, the anesthesia provider randomly selected one of these opaque concealed envelopes to ensure group randomization.

None of patients were premedicated. Non-invasive blood pressure monitoring device, pulse oximeter and electrocardiograph were attached to the patient as soon as they arrived in the operating room. All patients received spinal anesthesia at L3/4 or L4/5 level using $0.5 \%$ hyperbaric Marcaine
8-10 mg and fentanyl $20 \mu \mathrm{g}$ in the left lateral decubitus position. Hartmann's solution $10-15 \mathrm{ml} / \mathrm{kg}$ was administered before administration of carbetocin. The operation started as soon as the sensory block at level T4-T6 was confirmed.

A non-invasive hemodynamic monitoring cuff (Finometer ${ }^{\circledR}$, Finapres medical system, Netherlands) was attached to the patient's finger soon after the induction of spinal anesthesia. Using the Finometer, heart rate (HR) and mean arterial pressure (MAP) was recorded at every $15 \mathrm{~s}$ starting from $15 \mathrm{~s}$ before the administration of carbetocin to $5 \mathrm{~min}$ after.

After the removal of placenta, the bolus group received an intravenous bolus injection of carbetocin $100 \mu \mathrm{g}$ and the infusion group received $100 \mu \mathrm{g}$ carbetocin diluted in $50 \mathrm{ml}$ normal saline, over 5 min using an infusion pump (Orchestra ${ }^{\circledR}$ Module DPS, Fresenius Kabi, France). We defined hypotension as less than $20 \%$ of the preoperative value or below $80 \mathrm{mmHg}$ systolic blood pressure. Hypotension was treated with ephedrine $5 \mathrm{mg}$ boluses. If ephedrine was used during the study period, that patient would be excluded in study.

The primary endpoint was the mean difference in HR and MAP between study groups at each time point. The secondary endpoints were estimated blood loss (EBL), the presence of postoperative hemorrhage and the requirement for additional administration of uterotonic agent.

A MAP difference of $10 \mathrm{mmHg}$ between the two groups was considered clinically significant. According to the previous study reporting a standard deviation of $8.7 \mathrm{mmHg}$ [8], a sample of 17 patients per group was required with error of 0.05 and power of $90 \%$.

Demographic data variables including age, height, weight, and body mass index, ephedrine dose, and operation time were analyzed using unpaired $t$-tests. The primary endpoints were analyzed at each time point using unpaired $t$-tests. EBL of each group was compared using the Mann-Whitney test. Other secondary endpoints were compared using Fisher's exact test. All statistical analysis were performed using R software version 3.3.2 (R Core Team [2016]. R: A language and environment for statistical computing. R Foundation for Statistical Computing, Austria. URL: https://www.R-project.org/).

\section{RESULTS}

The study was conducted over a continuous period of 1 year. A total 34 patients were recruited. No patient was excluded except one whose data were missing (Fig. 1). The patient characteristics are shown in Table 1. No statistical 


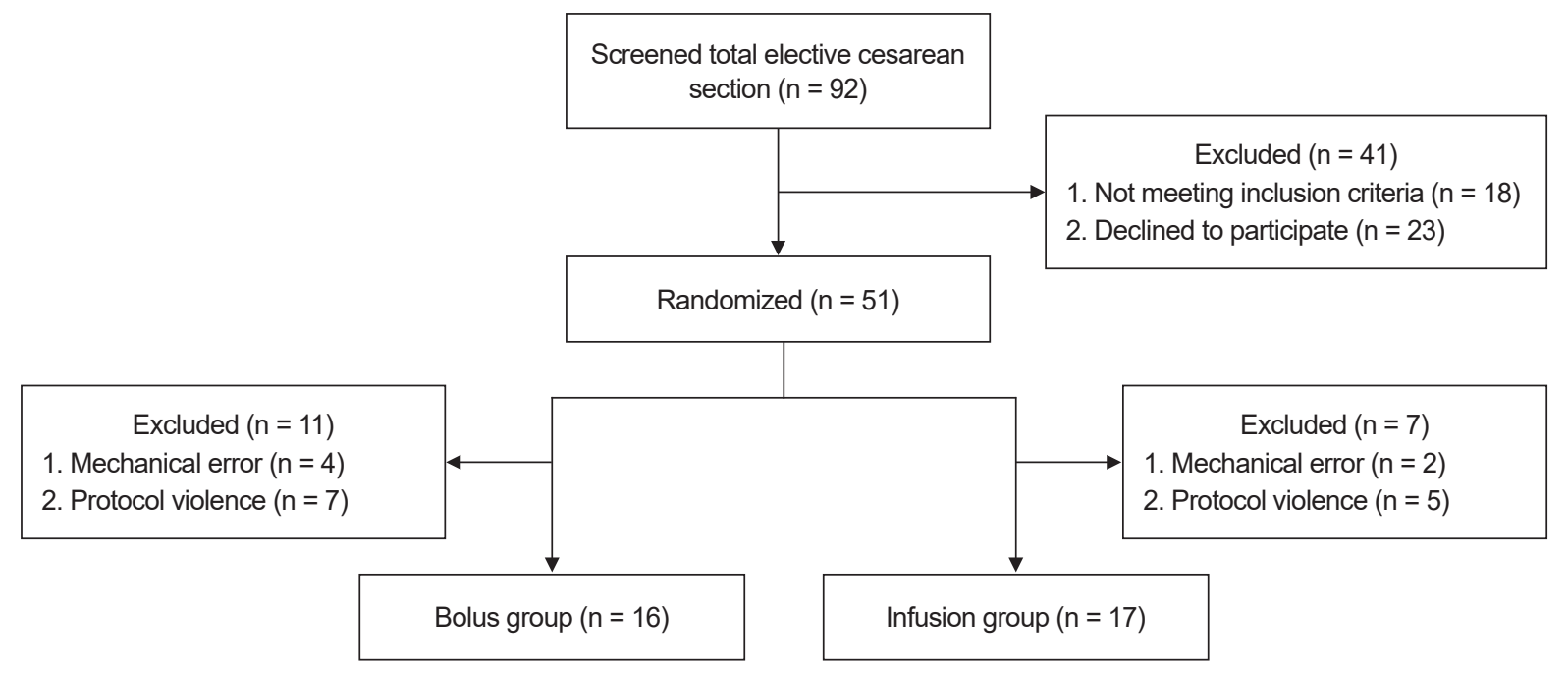

Fig. 1. Patients CONSORT flow chart.

Table 1. The Demographic Data of Two Groups

\begin{tabular}{lccc}
\hline \multicolumn{1}{c}{ Variable } & Bolus group $(\mathrm{n}=16)$ & Infusion group $(\mathrm{n}=17)$ & P value \\
\hline Age $(\mathrm{yr})$ & $33.8 \pm 3.1$ & $33.3 \pm 4.9$ & 0.721 \\
Height $(\mathrm{cm})$ & $159.6 \pm 6.3$ & $158.3 \pm 4.3$ & 0.469 \\
Weight $(\mathrm{kg})$ & $71.0 \pm 12.5$ & $66.3 \pm 12.3$ & 0.291 \\
Body mass index $\left(\mathrm{kg} / \mathrm{m}^{2}\right)$ & $27.7 \pm 3.9$ & $26.4 \pm 4.5$ & 0.390 \\
Indication for cesarean delivery & & & 6 \\
1. Previous cesarean section & 12 & 8 & 0.589 \\
2. Breech & 1 & $11.8 \pm 8.6$ & 14 \\
3. Others & 3 & $61.4 \pm 14.1$ & 0.354 \\
Ephedrine dose (mg) & $13.8 \pm 12.0$ & & \\
Number of ephedrine use & 13 & & \\
Operation time (min) & $65.9 \pm 13.5$ & & \\
\hline
\end{tabular}

Values are presented as mean \pm SD or number only.

difference was observed between the two groups in demographic data. None of patient received ephedrine during the study period and no difference in the total dose of ephedrine used between the two groups. Baseline HR and MAP were not statistically different either (Table 2).

Moreover, there was no statistical difference in the mean HR and MAP between the two groups (Figs. 2, 3). In both groups, we found a rapid decrease of MAP until $30 \mathrm{~s}$ after the administration of carbetocin regardless of the method of administration. Then, the trends showed a gradual increase. After $300 \mathrm{~s}$, the mean MAP of the bolus group was $\mathbf{8 8 . 7 3} \mathrm{mmHg}$ and that of the infusion group was $\mathbf{8 6 . 7 6}$ mmHg. The mean MAP of the bolus group was higher than that of the infusion group from 105 to $300 \mathrm{~s}$, but there was no statistically significant difference at any time point.

In both groups, we found a rapid increase of HR until 45 $\mathrm{s}$ after the administration of carbetocin. Then, the trends
Table 2. Initial Heart Rate and Mean Arterial Pressure of Two Groups

\begin{tabular}{lrc}
\hline Initial hemodynamic variable & Bolus group & Infusion group \\
\hline Initial HR (beats/min) & $83.6 \pm 15.3$ & $84.4 \pm 13.0$ \\
Initial MAP (mmHg) & $101.2 \pm 12.9$ & $97.6 \pm 13.5$ \\
\hline
\end{tabular}

Values are presented as mean \pm SD. HR: heart rate, MAP: mean arterial pressure.

showed a gradual decrease till the end of the study. After $300 \mathrm{~s}$, the mean HR of the bolus group was 92.35 beats/ min and that of the infusion group was 91.71 beats $/ \mathrm{min}$. Again, the difference between the two groups at any time point was not statistically significant. We also investigated EBL, additional administration of uterotonic agent in both groups and the incidence of postoperative intervention such as uterine artery embolization or hysterectomy (Table 3). There were no significant differences between the two groups. Only one patient received postoperative 


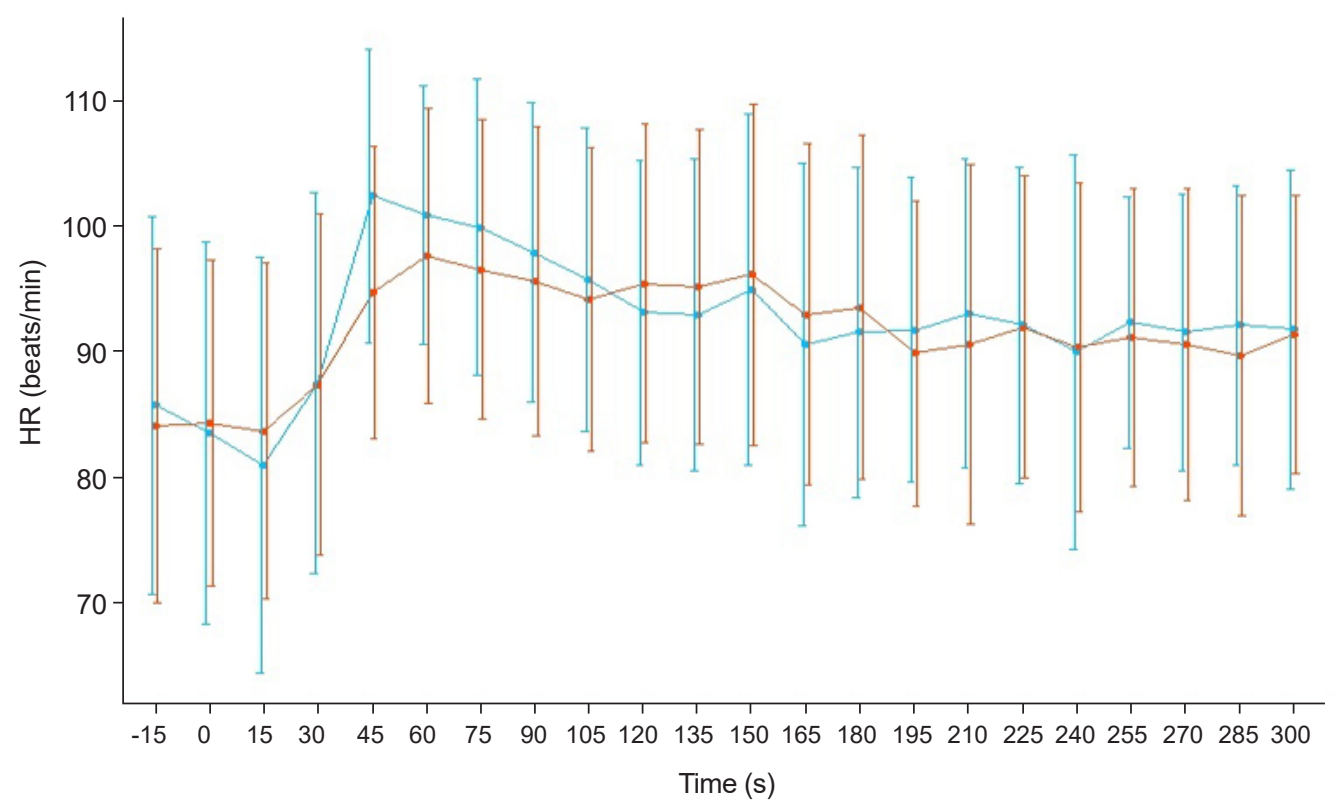

Fig. 2. The changes of heart rate (HR) in two groups. Values are presented as mean \pm SD.

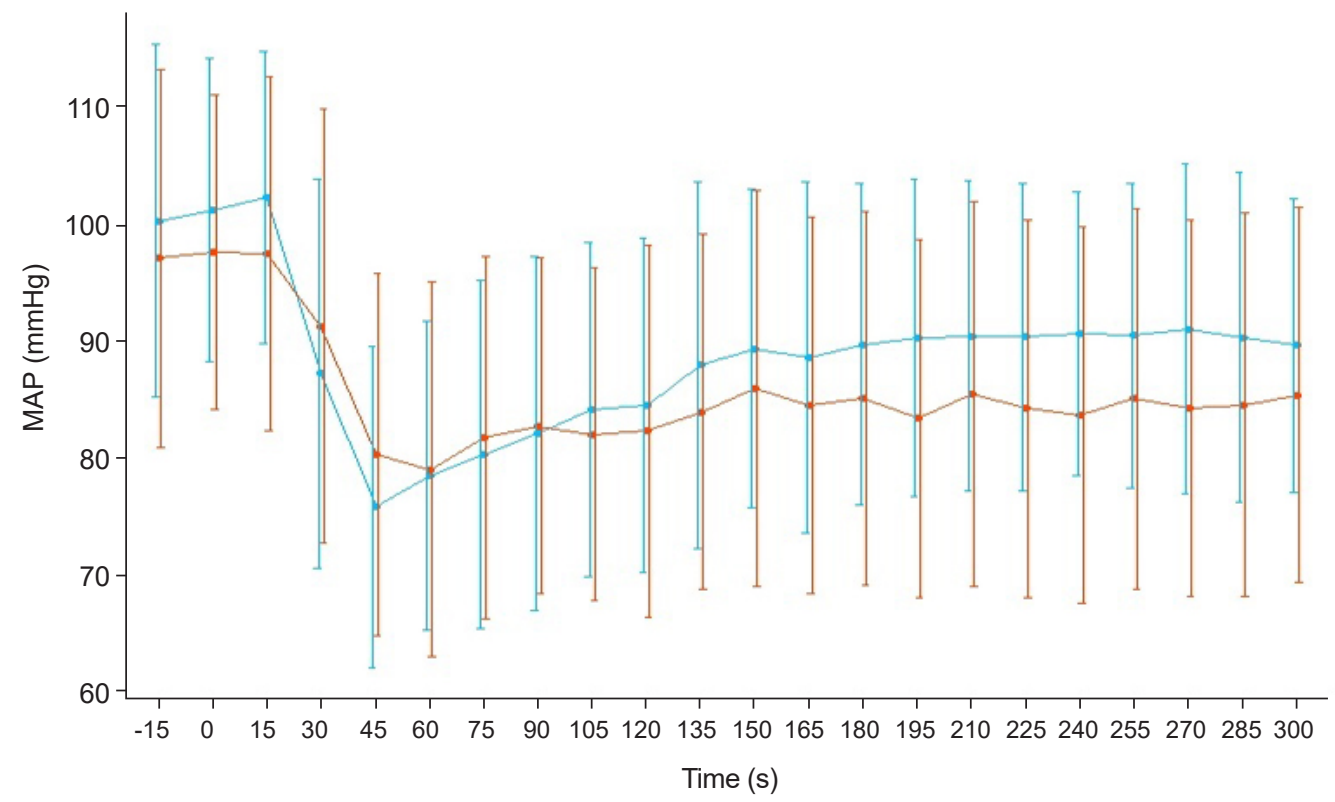

Group

$\rightarrow$ Bolus group

$\rightarrow$ Infusion group

Fig. 3. The changes of mean arterial pressure (MAP) in two groups. Values are presented as mean $\pm \mathrm{SD}$.

Table 3. Secondary Endpoint of Two Group

\begin{tabular}{lcc}
\hline \multicolumn{1}{c}{ Secondary endpoints } & Bolus group & Infusion group \\
\hline $\begin{array}{l}\text { Number of postoperative utero- } \\
\text { tonic agent }\end{array}$ & 0 & 0 \\
$\begin{array}{l}\text { Estimated blood loss }(\mathrm{ml}) \\
\begin{array}{l}\text { Number of postoperative } \\
\text { interventions }\end{array}\end{array}$ & $520.0 \pm 207.7$ & $535.3 \pm 264.4$ \\
$\begin{array}{l}\text { Number of patients received } \\
\text { transfusion }\end{array}$ & 0 & $1^{*}$ \\
\hline
\end{tabular}

Values are presented as number only or mean \pm SD. * 1 patient was received uterine artery embolization and the patients were also only patients received transfusion. uterine artery embolization and transfusion during PPH.

\section{DISCUSSION}

Our study showed that the method of administration of carbetocin does not influence its hemodynamic effects in cesarean section and does not affect additional uterotonic agent use or incidence of postoperative intervention such as uterine artery embolization or hysterectomy.

Carbetocin is a long-acting synthetic nonapeptide analogue of oxytocin with agonist properties. It can be admin- 
istered intravenously as a single dose immediately following vaginal delivery or cesarean section, to prevent uterine atony and postpartum hemorrhage. Similar to oxytocin, it selectively binds to oxytocin receptors present on the smooth musculature of the uterus, resulting in rhythmic contractions of the uterus, increased frequency of existing contractions, and increased uterine tone [11].

The Finometer ${ }^{\circledR}$ measures finger blood pressure noninvasively on a beat-to-beat basis and gives waveform measurements similar to those of intra-arterial recordings. One disadvantage is the measured value changes with the movement of the patient's finger or posture. However, its use is comfortable for conscious patients because it is non-invasive and the correlation can be easily calculated by measuring the brachial cuff pressure and hydrostatic height of the finger [12].

According to WHO guidelines for prevention of $\mathrm{PPH}$, oxytocin (10 IU, intravenous or intramuscular) is the uterotonic agent of choice during the third stage of labor and cesarean section. Although the use of carbetocin as an additional uterotonic agent has been recommended, according to WHO guidelines, carbetocin has no effect on the incidence of major obstetric hemorrhage and is more expensive than oxytocin [2].

Recent studies have suggested that carbetocin is superior to oxytocin in cost-effectiveness and prevention of PPH. van der Nelson et al. [10] compared the cost-effectiveness of carbetocin used for the prevention of PPH in cesarean section to that of oxytocin. They analyzed 1,500 patients receiving carbetocin or oxytocin in cesarean section and compared the costs for additional drugs and blood products used, which in turn depends on the incidence and severity of PPH. According to this study, in UK, the use of carbetocin instead of oxytocin reduced the costs by EUR 27,518. Jin et al. [13] examined 12 randomized controlled studies and found that carbetocin lowered the requirement for additional uterotonic agents and uterine massage in women who underwent cesarean section. However, their analysis could not detect a significant difference in PPH, EBL or adverse effects.

In the case of oxytocin, several reports have shown an association between an infusion of diluted oxytocin and milder hemodynamic changes compared to bolus administration. Thomas et al. [8] compared the effects of oxytocin administered as an intravenous bolus and as an infusion for $5 \mathrm{~min}$ in 30 women undergoing cesarean section. They reported marked cardiovascular changes in the bolus group. Kim et al. [14] also reported a similar result with regards to cardiovascular changes with a difference in the uterine tone and EBL.

Our study showed that the method of administration does not have a significant effect on the patient's hemodynamics in the case of carbetocin. Dell-Kuster et al. [15] investigated obstetric and hemodynamic differences between carbetocin bolus and infusion. They found that the administration of carbetocin as a short infusion does not compromise the uterine tone and that two methods have similar cardiovascular effects and vasoconstrictor dose requirements.

Intraoperative hypotension during spinal anesthesia for elective cesarean delivery are frequent above $70 \%$, when pharmacological prophylaxis is not used [16]. However, hypotension is prevented or improved by several methods such as prevention of aorto-caval compression, use of vasopressors and intravenous fluid loading. In our study, no occurrence of hypotension during the investigation period might be a result of a mere coincidence. But, we thought that sufficient fluid loading, the exclusion of emergency surgery and other effective treatment for preventing hypotension contributed to that result.

There were several limitations to this study. First, the calculated EBL of both groups were statistically similar, but there may have been a significant difference in the actual blood loss which is difficult to quantify $[17,18]$. A recent study recommends a colorimetric system for more accurate measurement of the amount of blood loss. Although we could not apply a colorimetric system, the difference in the actual blood loss between the two groups in our study is not expected to be large since the calculated EBL in the above mentioned study was similar to that of our study [18]. In the future, we aim to develop and optimize methods for the accurate measurement of blood loss and intravascular volume status. Furthermore, this study does not investigate postoperative hemodynamic change. Although there were no differences between the two groups in terms of additional uterotonic drug use or postoperative complications, it is necessary to measure postoperative vital sign for investigating the precise hemodynamic effect of carbetocin.

In conclusion, the administration method of carbetocin does not influence the hemodynamic changes. In addition, the administration method has no effect on postoperative complications, additional administration of uterotonic agents or blood loss. 


\section{CONFLICTS OF INTEREST}

No potential conflict of interest relevant to this article was reported.

\section{AUTHOR CONTRIBUTIONS}

Conceptualization: Kyung Ok Kim. Data acquisition: Kihyug Kwon, Kyung Ok Kim. Formal analysis: Dohyung Kim, Hyunmin Jo, Ji Eun Park. Supervision: Kyung Ok Kim. Writing_original draft: Dohyung Kim, Hyunmin Jo. Writingreview \& editing: Kihyug Kwon, Ji Eun Park.

\section{ORCID}

Kihyug Kwon, https://orcid.org/0000-0001-7766-7178

Dohyung Kim, https://orcid.org/0000-0001-8245-8995

Hyunmin Jo, https://orcid.org/0000-0002-0957-8488

Ji Eun Park, https://orcid.org/0000-0002-2466-7040

Kyung Ok Kim, https://orcid.org/0000-0001-7509-3668

\section{REFERENCES}

1. Say L, Chou D, Gemmill A, Tunçalp Ö, Moller AB, Daniels J, et al. Global causes of maternal death: a WHO systematic analysis. Lancet Glob Health 2014; 2: e323-33.

2. World Health Organization. WHO recommendations for the prevention and treatment of postpartum haemorrhage. Geneva: World Health Organization. 2012, 41 p.

3. Knight M, Callaghan WM, Berg C, Alexander S, Bouvier-Colle $\mathrm{MH}$, Ford JB, et al. Trends in postpartum hemorrhage in high resource countries: a review and recommendations from the International Postpartum Hemorrhage Collaborative Group. BMC Pregnancy Childbirth 2009; 9: 55.

4. Meshykhi LS, Nel MR, Lucas DN. The role of carbetocin in the prevention and management of postpartum haemorrhage. Int J Obstet Anesth 2016; 28: 61-9.

5. Petersson M. Cardiovascular effects of oxytocin. Prog Brain Res 2002; 139: 281-8.

6. Shahin J, Guharoy SR. Pulmonary edema possibly developing secondary to the intravenous administration of oxytocin. Vet Hum Toxicol 1991; 33: 587-8.

7. Ghai B, Vayjnath AM, Lal S. Acute pulmonary oedema follow- ing oxytocin administration: a life threatening complication. J Indian Med Assoc 2006; 104: 261-2.

8. Thomas JS, Koh SH, Cooper GM. Haemodynamic effects of oxytocin given as i.v. bolus or infusion on women undergoing Caesarean section. Br J Anaesth 2007; 98: 116-9.

9. Moertl MG, Friedrich S, Kraschl J, Wadsack C, Lang U, Schlembach D. Haemodynamic effects of carbetocin and oxytocin given as intravenous bolus on women undergoing caesarean delivery: a randomised trial. BJOG 2011; 118: 1349-56.

10. van der Nelson HA, Draycott T, Siassakos D, Yau CWH, Hatswell AJ. Carbetocin versus oxytocin for prevention of post-partum haemorrhage at caesarean section in the United Kingdom: an economic impact analysis. Eur J Obstet Gynecol Reprod Biol 2017; 210: 286-91.

11. Sweeney G, Holbrook AM, Levine M, Yip M, Alfredsson K, Cappi S, et al. Pharmacokinetics of carbetocin, a long-acting oxytocin analogue, in nonpregnant women. Curr Ther Res Clin Exp 1990; 47: 528-40.

12. Schutte AE, Huisman HW, van Rooyen JM, Malan NT, Schutte R. Validation of the Finometer device for measurement of blood pressure in black women. J Hum Hypertens 2004; 18: 7984.

13. Jin B, Du Y, Zhang F, Zhang K, Wang L, Cui L. Carbetocin for the prevention of postpartum hemorrhage: a systematic review and meta-analysis of randomized controlled trials. J Matern Fetal Neonatal Med 2016; 29: 400-7.

14. Kim TS, Bae JS, Park JM, Kang SK. Hemodynamic effects of continuous intravenous injection and bolus plus continuous intravenous injection of oxytocin in Cesarean section. Korean J Anesthesiol 2011; 61: 482-7.

15. Dell-Kuster S, Hoesli I, Lapaire O, Seeberger E, Steiner LA, Bucher HC, et al. Efficacy and safety of carbetocin given as an intravenous bolus compared with short infusion for Caesarean section - double-blind, double-dummy, randomized controlled non-inferiority trial. Br J Anaesth 2017; 118: 772-80.

16. Mercier FJ, Augè M, Hoffmann C, Fischer C, Le Gouez A. Maternal hypotension during spinal anesthesia for caesarean delivery. Minerva Anestesiol 2013; 79: 62-73.

17. Lopez-Picado A, Albinarrate A, Barrachina B. Determination of perioperative blood loss: accuracy or approximation? Anesth Analg 2017; 125: 280-6.

18. Doctorvaladan SV, Jelks AT, Hsieh EW, Thurer RL, Zakowski MI, Lagrew DC. Accuracy of blood loss measurement during Cesarean delivery. AJP Rep 2017; 7: e93-100. 